\title{
Age and growth in paralarvae of the mesopelagic squid Abralia trigonura based on daily growth increments in statoliths
}

\author{
Keith A. Bigelow* \\ Department of Oceanography, School of Ocean and Earth Science and Technology (SOEST), University of Hawaii at Manoa, \\ Honolulu, Hawaii 96822, USA
}

\begin{abstract}
Growth increments in statoliths were used to estimate the age of 55 Abralia trigonura (Berry, 1913), a small tropical mesopelagic enoploteuthid squid collected from Hawaiian waters in 1988 and 1989. Growth increments were examined with light and scanning electron microscopy. Daily periodicity of increment formation and the statolith size at hatching were confirmed by rearing hatchlings in the laboratory. Mantle length (ML) at age data suggested that paralarvae grew exponentially at a rate of $5.9 \% \mathrm{ML} \mathrm{d}^{-1}$ for ca $40 \mathrm{~d}$ post-hatching, while post-paralarvae exhibited slower growth. No significant difference in growth was noted between paralarvae collected from spatially or temporally separated samples, though estimated length differed at hatching. Estimated paralarval mortality was $7.0 \% \mathrm{~d}^{-1}$. Within statolith microstructures, a transition in increment widths occurred at an average of 41.5 increments, which corresponded to $10.9 \mathrm{~mm} \mathrm{ML}$. The transition probably represents the end of the paralarval period, which is marked by a shift from an epipelagic to a mesopelagic habitat.
\end{abstract}

\section{INTRODUCTION}

Oceanic squid (Teuthoidea: Oegopsida) generally have planktonic young (paralarvae) that are typically confined to the near-surface waters ( 0 to $200 \mathrm{~m}$ ) of the epipelagic zone (Young \& Harman 1988). Paralarval squid spend an unknown length of time in the plankton and then typically descend to an adult habitat in the mesopelagic (400 to $1200 \mathrm{~m}$ ) or bathypelagic (>1200 m) zone (Roper \& Young 1975), although some species (e.g. Thysanoteuthis rhombus) may remain in epipelagic waters as adults. Variation in mortality rate during the planktonic period could have considerable influence on population abundance. Small declines in paralarval growth rates may lead to a substantially longer planktonic period over which high mortality rates are presumed to operate. In larval fishes, intraspecific variability in grow th rates can cause large

\footnotetext{
- Present address: Honolulu Laboratory, Southwest Fisheries Science Center, National Marine Fisheries Service, NOAA. 2570 Dole Street, Honolulu, Hawaii 96822-2396, USA.
}

differences in survival, which will relate to recruitment variability in adult populations (Houde 1987). Similar relationships between larval survival and recruitment presumably exist for squids. Paralarval growth rates and duration of planktonic life, however, are unexplored aspects of the early life history of squids.

Determination of growth rates and duration of the paralarval stage require accurate age estimates. In exploited squid populations, age and growth have sometimes been inferred from analysis of lengthfrequency distributions (e.g. Squires 1967, Summers 1971). Analysis of length-frequency distributions is usually futile for tropical and subtropical squid populations, which may spawn throughout the year, making length-frequency modes difficult or impossible to detect. An alternative method for age estimation has focused on statoliths, which contain microscopic growth increments. Statoliths have been successfully used for age analysis because the periodic features within the microstructure of statoliths can be related to actual time periods (see review by Rodhouse \& Hatfield 1990). 
During the late 1970 s and early 1980 s, various researchers (Spratt 1978, Lipinski 1978, 1980, Kristensen 1980, Rosenberg et al. 1981, Morris \& Aldrich 1985) reported the occurrence of increments in statoliths of a variety of loliginid and ommastrephid species, but could not clearly demonstrate that increments were deposited daily.

In more recent years, studies have attempted to establish the frequency of increment formation. Validation procedures include correlating lengthfrequency data with statolith analysis (Radtke 1983, Natsukari et al. 1988), using known-age laboratory specimens (Yang et al. 1986) or placing marks on the statolith and rearing individuals for a known time period (Dawe et al. 1985, Lipinski 1986, Jackson 1989, 1990, Nakamura \& Sakurai 1990). These 8 studies have provided validation of the frequency of increment formation in 2 orders of cephalopods (Teuthoidea and Sepioidea), which suggests daily increment formation in statoliths may be common to many cephalopod species. Enumeration of daily increments from these studies provides longevity estimates of 4 to $12 \mathrm{mo}$, suggesting that squids are fast-growing, short-lived animals.

The objective of this paper is to assess the utility of statolith microstructures in studying the early life history of Abralia trigonura (Berry, 1913), a small (<45 mm mantle length), muscular enoploteuthid squid. As an adult, this species occupies a mesopelagic habitat in the day and undertakes diel vertical migration at dusk and dawn. This study examines the spatial and temporal variation in growth rates of paralarvae and estimates mortality within the early life history through enumeration of growth increments in statoliths. Also, a change in increment width in the statoliths appears to mark the transition to the mesopelagic habitat

\section{MATERIALS AND METHODS}

Collection of squid for age analysis. Plankton samples were taken in November 1988 off windward Oahu, Hawaii, over bottom depths between 700 and $1500 \mathrm{~m}$ (Fig. 1). Oblique tows to $150 \mathrm{~m}$ were taken with a $4 \mathrm{~m}^{2}$ ring net. The net was equipped with $505 \mu \mathrm{m}$ mesh, a TSK flowmeter and a Benthos time-depth recorder (TDR). Plankton samples were also taken in November 1989 off windward and leeward Oahu (Fig 1). For the 1989 samples, a $0.8 \mathrm{~m}^{2}$ ring net with $505 \mu \mathrm{m}$ mesh was towed obliquely to $100 \mathrm{~m}$, over a bottom depth of about $500 \mathrm{~m}$. In both years, paralarval squid were sorted from the plankton on board ship with a Zeiss stereomicroscope and were immediately preserved in $95 \%$ ethyl alcohol. Dorsal mantle length

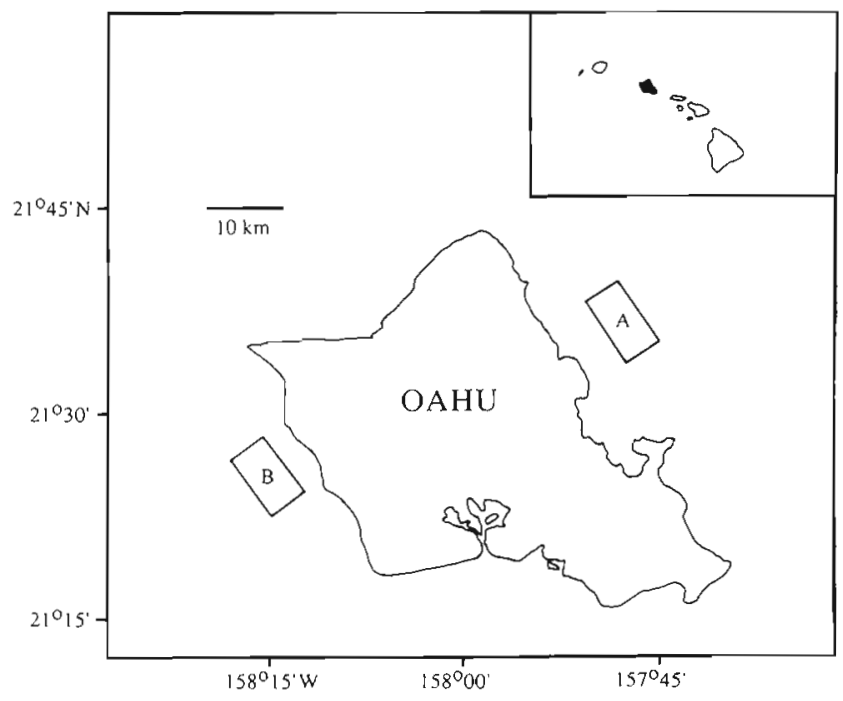

Fig. 1 Location of study areas off (A) windward and (B) leeward Oahu, Hawaii

(ML) of each preserved specimen was measured to $0.1 \mathrm{~mm}$ by an ocular micrometer with a stereomicroscope. There was no attempt to account for shrinkage due to tissue dehydration in ethanol.

Juvenile, subadult and adult squids were collected on 2 occasions with 2 types of open nets: a $100 \mathrm{~m}^{2}$ rope trawl and a $40 \mathrm{~m}^{2}$ rectangular midwater trawl (RMT-40). Both nets were equipped with an acoustic depth telemeter to monitor and adjust trawl depth. Trawl depth was confirmed with a Benthos TDR. In April 1988, oblique rope trawl samples to $250 \mathrm{~m}$ were taken at night off windward Oahu over a depth of about $700 \mathrm{~m}$ (Fig. 1). Oblique RMT-40 samples were taken in October-November 1989 off leeward Oahu over a depth of about $800 \mathrm{~m}$ (Fig. 1). In each sampling program, squids were sorted from the catch and preserved in $95 \%$ ethyl alcohol.

Validation of ageing methodology. Reared paralarvae of Abralia trigonura were used to determine the size of the statolith at hatching, to ascertain when the first growth increment was formed and to validate if increments were deposited daily. Squid eggs with developing embryos were caught in plankton samples taken in the October-November 1989 sampling off windward and leeward Oahu (Fig. 1). Eggs were sorted from the plankton on board ship using stereomicroscopes. Each egg was placed in $1.5 \mathrm{ml}$ of $0.2 \mu \mathrm{m}$ filtered seawater within tissue culture trays. After hatching, paralarvae were transferred to $1 \mathrm{l}$ glass jars of filtered seawater, placed on a plankton rotator, and reared under a $12 \mathrm{~h}$ light $12 \mathrm{~h}$ dark photoperiod at a temperature of 22 to $24^{\circ} \mathrm{C}$. Throughout the rearing experiment, no attempt was made to feed the paralarvae. After isolation, paralarvae were sequentially 
sacrificed by fixing in $95 \%$ ethyl alcohol at $24 \mathrm{~h}$ intervals over an $8 \mathrm{~d}$ period. The correlation between the number of statolith growth increments and the rearing period was described by type I linear regression (ANOVA, Sokal \& Rohlf 1981). To test the hypothesis of daily increment formation, the slope of the regression equation was compared to an expected value of 1.0 using a Student's t-test (Sokal \& Rohlf 1981).

Laboratory procedures. Statoliths were removed from the specimens with fine dissecting needles and forceps under a stereomicroscope. First, the funnel was removed and the statocyst was torn away from the cephalic cartilage. Statoliths could be seen as paired, white, opaque structures within the statocyst. The statocyst was pulled apart, allowing the statoliths to fall onto a microscope slide, where they were rinsed in distilled water and allowed to dry.

Terms used to describe the external morphological features of a statolith follow Clarke (1978). The statolith consists of 4 basic parts: dorsal dome, lateral dome, rostrum and the wing or attachment area. Statoliths were mounted on a microscope slide in Eukitt resin. Paralarval statoliths were mounted with the anterior (concave) side positioned upward; juvenile, subadult and adult statoliths were mounted with the edge of the lateral dome touching the microscope slide and the wing positioned upward. Statoliths were oriented into the preferred position while the resin polymerized, which took about 5 min.

The terminology in Lipinski et al. (1991) is used to describe statolith microstructures. The focus is the point where aragonite crystals are initially accreted. When viewed with light microscopy, an increment consists of a narrow dark (refractile) ring and a wide, light (translucent) ring. The region between the focus and the first dark ring is the nucleus. The natal ring is the dark ring corresponding to statolith size at hatching.

Statolith dimensions were determined with an image analysis system (Campana 1987) interfaced with a Zeiss compound microscope. The digitized microscopic statolith images $(400 \times)$ enabled the measurements of focus-dorsal dome length, focus-rostral length, total length between the dorsal dome and rostrum and increment widths along a transect from the natal ring to the dorsal region of the lateral dome (Fig. 2).

Microstructures were examined in whole mounted or ground preparations with light and scanning electron microscopy (SEM). Under a compound microscope $(400 \times)$, increments were counted from the natal ring to the outer margin in the direction of the lateral dome. I conducted counts on 2 separate occasions and averaged for a mean increment value. All increment counts were replicated with no prior knowledge of the previous increment count.

For most of the specimens, at least 1 statolith of the pair was examined with SEM. The embedded statolith, mounted on a glass slide, was ground by hand with fine-grained (1200 grit) sandpaper. The statolith was then polished with $0.3 \mu \mathrm{m}$ alumina-silica polishing powder, etched for 2 to 15 min with $0.1 \%$ EDTA ( $\mathrm{ph}$ adjusted to 7.9 with $\mathrm{NaOH}$ ), and coated with gold in a Technics vacuum evaporator. Statolith microstructures were viewed and photographed with an ISI SS40 SEM at various magnifications (100 to $10000 \times)$. From each SEM photograph, increments were counted from the natal ring to the outer margin,

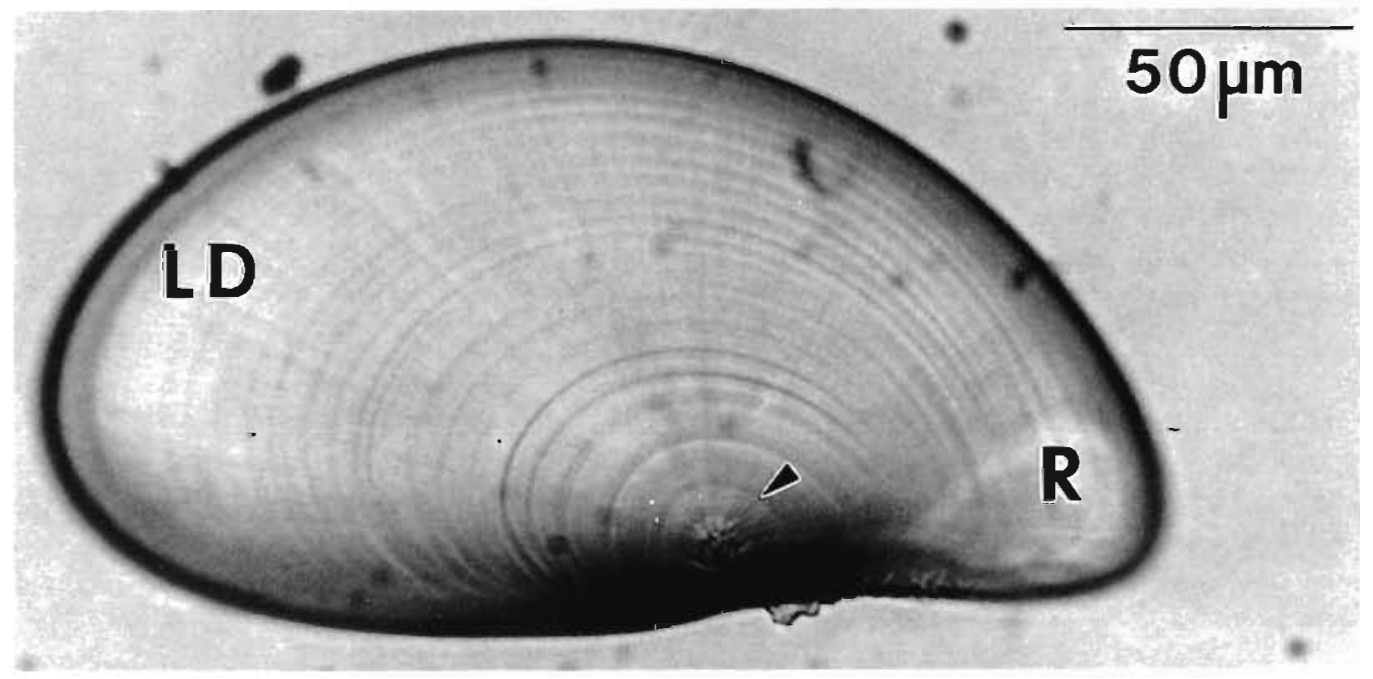

Fig. 2. Abralia trigonura. Light micrograph of a statolith from a $3.5 \mathrm{~mm} \mathrm{ML}$ paralarva. LD: lateral dome; R: rostrum; arrow indicates location of natal ring. Duplicate increment counts were 19 and 20 
in the direction of the lateral dome. I read photographs on 2 separate occasions, and the increment counts were averaged.

Mantle length at age data of field-caught paralarval squid were fit by least squares regression to the following equations: linear, $Y=a+b x_{i}$ power, $Y=a x^{b}$; exponential, $Y=a \mathrm{e}^{b x}$; and $\log , Y=a+\log x_{i}$ where $Y=$ mantle length ( $\mathrm{mm}$ ) and $X=$ age (d). Differences in growth curves between spatially and temporally separated samples were compared with analysis of covariance (ANCOVA) and F-tests (Sokal \& Rohlf 1981). Data were initially ln-transformed, and ANCOVA was used to test for differences in slopes of the linearized growth equations. Differences in slopes were considered significant if $p<0.05$. Elevations of the linearized growth equations were compared with $F$-tests. Because of the multiple comparisons, the level of significance was adjusted to 0.016 by the DunnSidak formula (Sokal \& Rohlf 1981).

Mortality rate estimation. Estimation of the mortality rate was calculated by the decline of age groups over a sampling period using a modification of a procedure developed by Sette (1943). Mantle lengths of Abralia trigonura were measured from $4 \mathrm{~m}^{2}$ oblique ( 0 to $300 \mathrm{~m}$ ) samples $(\mathrm{n}=94)$ collected during March 22 to 31, 1986, off leeward Oahu over a depth of about $2000 \mathrm{~m}$. Abundance was standardized to a surface area of $1000 \mathrm{~m}^{2}$ Abundance at length data were averaged for day $(n=46)$ and night $(n=48)$ samples in $1.0 \mathrm{~mm}$ $\mathrm{ML}$ intervals, to test for differences in net avoidance. Because no significant difference was found between the day-night size-frequency distributions (Kolmogorov-Smirnov test, $\mathrm{p}=0.20$ ), data were pooled over day and night for mortality estimation. Length frequencies were converted to age frequency groups by a regression of age against ML from the November 1988 growth estimate. Iterated ALK methods (Kimura

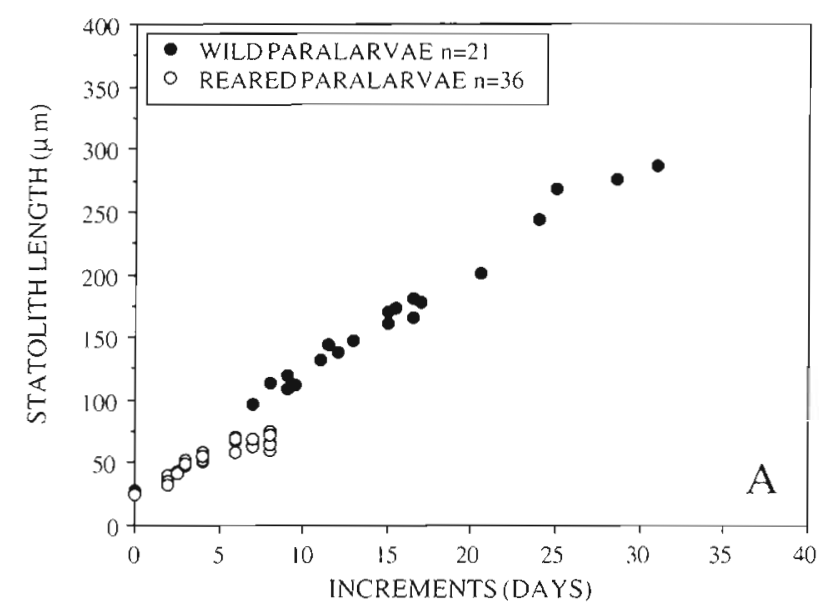

$\&$ Chikuni 1987) were not appropriate for length to age conversions, due to the small ageing sample ( $n=24)$. Summation of age groups from all the specimens $(n=307)$ resulted in a histogram of age frequencies over the sampling period. Instantaneous daily mortality was estimated as the negative slope of the lntransformed age frequency curve: $\ln \left(N_{t}\right)=\ln \left(N_{0}\right)-Z t_{i}$ where $Z=$ the instantaneous mortality coefficient, $N_{t}=$ number of paralarvae of age group $t$ and $t=$ time in days. Confidence intervals of $95 \%$ for the mortality estimate were computed by standard regression techniques (Sokal \& Rohlf 1981).

\section{RESULTS}

\section{Validation of ageing techniques}

Rearing experiments showed that paralarvae had statoliths at the time of hatching with an average radius of $12.7 \mu \mathrm{m}(\mathrm{n}=4, \mathrm{SD}=0.8 \mu \mathrm{m})$. Statoliths increased in size throughout the $8 \mathrm{~d}$ rearing period (Fig. 3A), although growth was slow after Day 6. The focus could often be observed with light microscopy, but increments could not be reliably counted because dark rings were weak and poorly resolved; therefore, all microstructural examinations were made with SEM. The statolith size at hatching was estimated as the microstructural feature that had a radius of 12 to $13 \mu \mathrm{m}$, then all subsequent increments were enumerated (Fig. 4A). Overall, increments within statoliths of reared paralarvae were difficult to discern, especially the peripheral increments of older (>6 d) paralarvae which were relatively narrow compared to increments near the focus (compare below with field-caught specimens). In 3 of the specimens $(20 \%), 1$ increment occurred between the focus and the natal ring

Fig. 3. Abralia trigonura. (A) Comparison of statolith total length from laboratory-reared and field-caught paralarvae, and (B)

relationship between statolith lengths and number of daily growth increments for all squid size classes

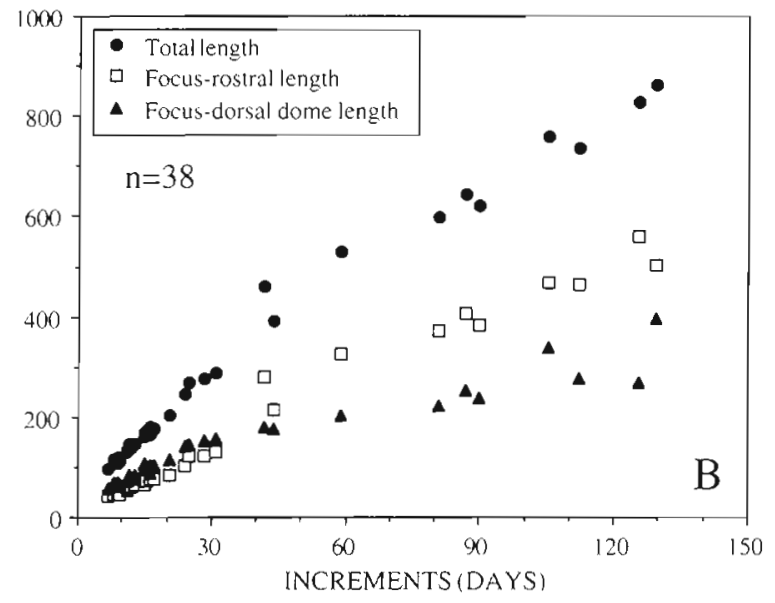


(Fig. 4A). A close correlation existed between the rearing period and the number of increments deposited, and the slope of the regression equation ( $b=0.875$, Fig. 5) does not differ significantly from an expected value of 1.0 .

\section{Analysis of statolith dimensions and microstructures}

Statoliths from a total of 55 field-caught Abralia trigonura paralarvae, juveniles, subadults and adults were used for age analysis. The SEM examination showed that an increment appeared as a relatively wide, lightly etched area (light ring) and a narrow, deeply etched area (dark ring, Fig. 4B). The natal ring from field-caught paralarval statoliths was similar in size (radius $=12 \mu \mathrm{m}$ ) to the statoliths of hatched paralarvae from the rearing experiment. The first few increments immediately peripheral to the natal ring were sometimes difficult to resolve, similar to those in the laboratory-reared paralarvae. Some of the statoliths had less distinct increments between more prominent increments; they were assumed to be subdaily, were frequently seen on the rostrum and were
Fig. 4. Abralia trigonura. Scanning electron micrographs. (A) Ground and etched statolith from a paralarva reared for 2 d. Arrow indicates natal ring formed at time of hatching. Two post-hatching increments are indicated. One increment was deposited during embryological development. (B) A statolith from a $4.8 \mathrm{~mm}$ ML paralarva, as used for increment enumeration. Duplicate increment counts were 25 and 25
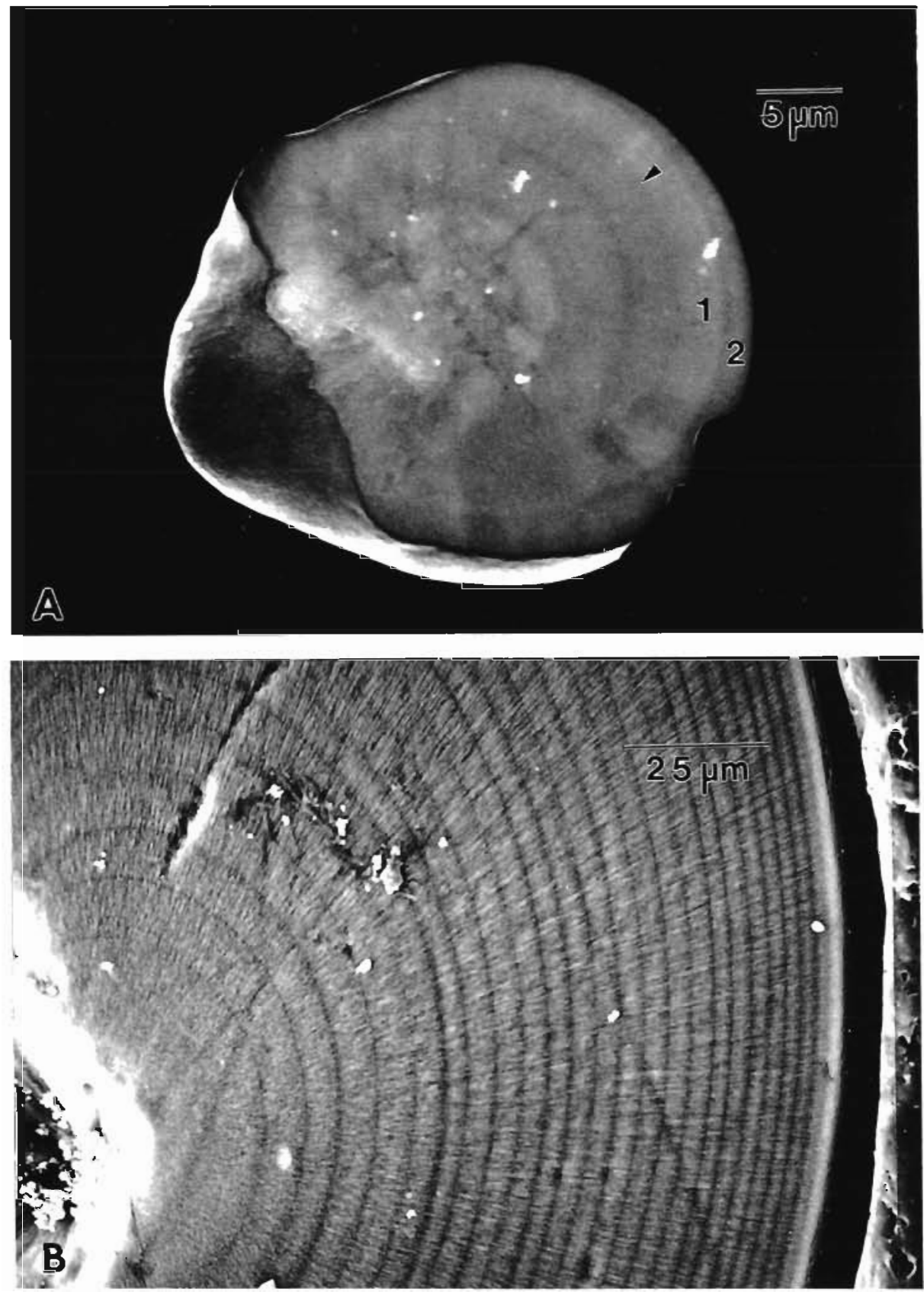


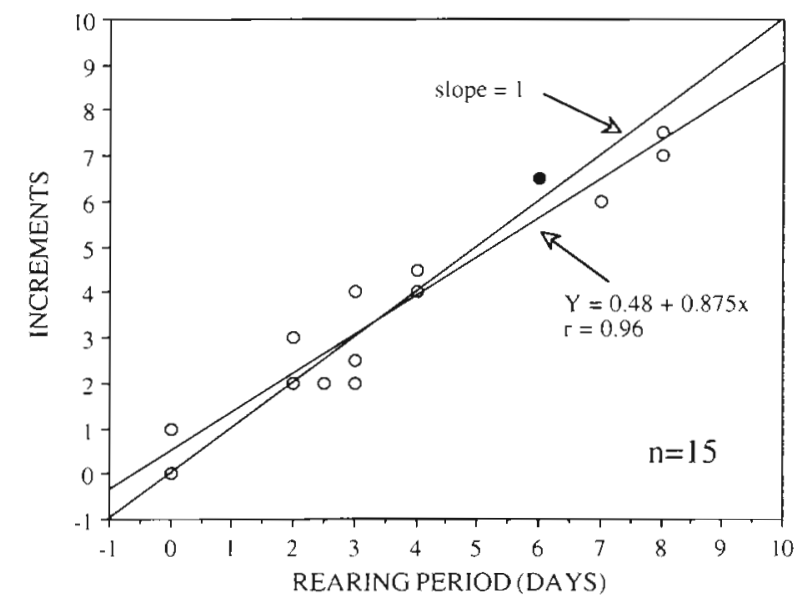

Fig. 5. Abralia trigonura. Comparison of the number of growth increments deposited in statoliths of paralarvae and rearing period. - indicates a duplicate observation

less apparent on the lateral dome (Fig. 2). Increments were always enumerated from the natal ring to the dorsal or lateral edge of the lateral dome (Fig. 4B), which provided a less ambiguous interpretation compared to the rostral zone.

Statoliths of 24 field-caught paralarvae $(1.3$ to $6.8 \mathrm{~mm} \mathrm{ML}$ ) were examined from collections taken in November 1988. At $8 \mathrm{~d}$ post-hatching, statolith total lengths of field-caught paralarvae were larger (114 $\mu \mathrm{m})$ than statoliths from laboratory-reared paralarvae $(70 \mu \mathrm{m}$, Fig. 3A). Increments were clearly present and were counted with light microscopy and SEM. For both microscopy methods, no significant difference was found between the first and second increment counts ( $t$-test, $p>0.05$ ). Counting error in both light microscopy and SEM for field-caught paralarvae was small, as the coefficient of variation about the mean count averaged $5.9 \%$ for light microscopy and $1.8 \%$ for SEM. The error associated with light microscopy is greater than SEM, because of reduced clarity of peripheral increments due to optical distortion of transmitted light through the statolith. No significant difference was found between mean increment counts from light microscopy and SEM ( $p>0.05)$.

A good relationship existed between the number of growth increments counted by SEM and squid ML

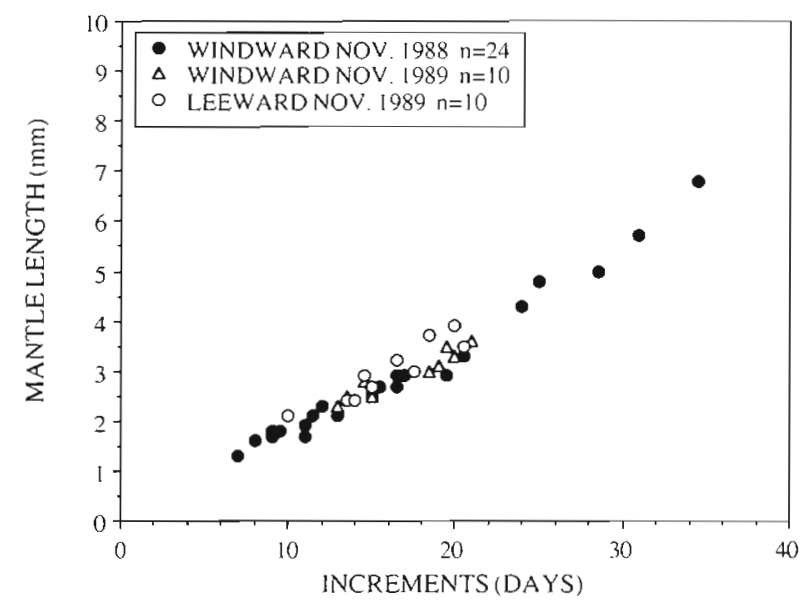

Fig. 6. Abralia trigonura. Comparison between mantle length and number of daily growth increments in statoliths of fieldcaught paralarvae collected off windward (1988 and 1989) and leeward (1989) Oahu, Hawaii

(Fig. 6). A linear and exponential function fit the length data equally well $\left(\mathrm{r}^{2}=0.97\right)$ and only slightly better than a power function $\left(r^{2}=0.96\right)$, but the exponential function (Table 1: Eq. 1) best described paralarval growth because the $y$-intercept of the exponential function $(a=1.03 \mathrm{~mm} \mathrm{ML})$ was very close to actual hatching length $(1.2 \mathrm{~mm})$ compared to linear $(a=$ $-0.15 \mathrm{~mm}$ ML) and logarithmic ( $a=0.19 \mathrm{~mm} \mathrm{ML})$ functions. The exponential function suggests that paralarvae grow at a rate of $5.9 \% \mathrm{ML} \mathrm{d}^{-1}$.

Twenty additional statoliths were examined from paralarvae sampled in November 1989 off windward $(n=10)$ and leeward $(\dot{n}=10)$ Oahu. Increment counts from these samples were determined by light microscopy, and their resulting exponential growth curves were similar between these spatially separated samples (Fig. 6, Table 1). The slopes of the linearized forms of the 3 growth curves did not differ significantly $(p>0.05)$. Pair-wise tests of the 3 samples revealed no significant difference in elevations ( $y$-intercepts) of the growth curves between the windward 1988-windward 1989 or windward 1989-leeward 1989 data sets ( $p>0.016)$, but the $y$-intercept of the windward Oahu 1988 growth curve $(1.03 \mathrm{~mm})$ differed significantly from the leeward Oahu 1989 growth curve $(1.13 \mathrm{~mm}$, $\mathrm{p}<0.016$ ). Based on the growth relationships (Table 1:

Table 1. Abralia trigonura. Growth in mantle length (ML) for field-caught paralarval squid. Growth equations are based on ML at age $(x)$ relationships

\begin{tabular}{lcccccc|}
\hline Location & Year & $\mathrm{n}$ & $\mathrm{ML}(\mathrm{mm})$ & $\mathrm{r}^{2}$ & Age period (d) & Equation no. \\
\hline Windward & 1988 & 24 & $1.03 \mathrm{e}^{0.057 x}$ & 0.97 & $7-35$ & 1 \\
\multirow{2}{*}{ Leeward } & 1989 & 10 & $1.22 \mathrm{e}^{0.051 x}$ & 0.92 & $13-21$ & 2 \\
\hline
\end{tabular}


Eqs. $1 \& 3$ ), the difference in hatching sizes can influence the growth of paralarvae, as paralarvae that developed off windward Oahu in 1988 grew to a length of $3 \mathrm{~mm} \mathrm{ML}$ in $18.7 \mathrm{~d}$, whereas off leeward Oahu in 1989, paralarvae grew to $3 \mathrm{~mm} \mathrm{ML}$ in $16.4 \mathrm{~d}$.

\section{Life-history transition}

Statoliths were examined from post-paralarval Abralia trigonura (i.e. late juveniles, subadults and adults) ranging in size from 10.5 to $42.0 \mathrm{~mm}$ ML. Increments were counted using SEM on 10 individuals and ranged from 42 to 130 increments. Extrapolation of the paralarval growth equation (Table 1: Eq. 1) over the post-paralarval size range suggests that only 2 individuals ( 10.5 and $12.5 \mathrm{~mm} \mathrm{ML}$ ) were near the curve (Fig. 7); therefore, by a length of at least $16.0 \mathrm{~mm} \mathrm{ML}$ exponential growth has been replaced by a slower growth phase. A linear curve fitted to post-paralarval length at age estimates intercepts the paralarval curve at a ML of $11.2 \mathrm{~mm}$. The linear curve is not intended to describe the form of post-paralarval growth, which is the subject of a separate study (Young \& Mangold unpubl.), but rather to estimate the size at which a transition in growth occurs.

The widths of 70 increments from the natal ring to the dorsal dome were determined for 11 individuals. Increments were widest around the natal region, where the initial 20 increments had widths greater than $4 \mu \mathrm{m}$ (Fig. 8). The widths of the initial 20 increments were highly variable between specimens. After the first series of increments, mean increment width decreased to ca $1.5 \mu \mathrm{m}$. This transition zone occurred

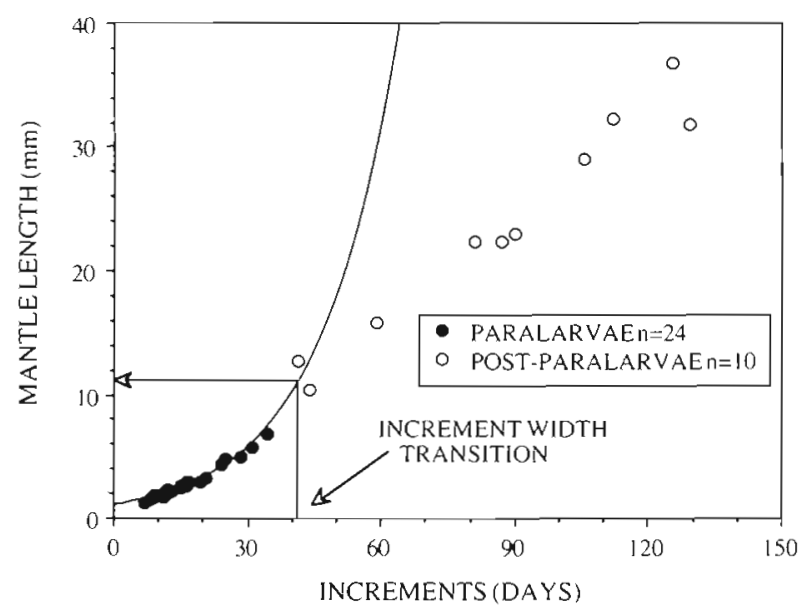

Fig. 7 Abralia trigonura. Age at mantle length estimates for paralarvae and post-paralarvae (i.e. juveniles, subadults and adults). The exponential curve is fitted to paralarval data. The arrow indicates the mean age ( $41.5 \mathrm{~d})$ at which a transition in increment width occurs in statolith microstructures

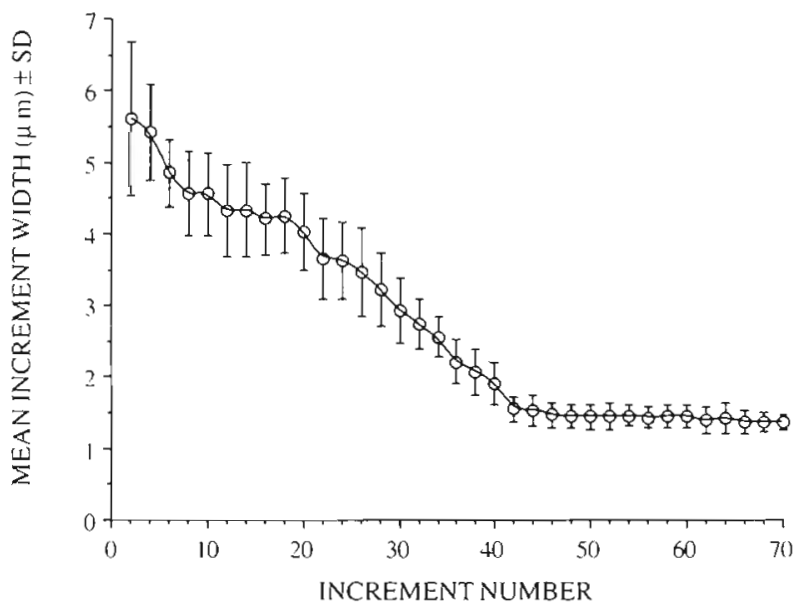

Fig. 8. Abralia trigonura. Mean increment width and increment number at $2 \mathrm{~d}$ intervals as counted from the natal ring.

Each point is the mean of 11 individuals; error bars $=S D$

at an average of 41.5 increments ( $S D=2.80,95 \%$ confidence limits $=39.6$ and 43.3 ) and ranged from 38 to 47 increments. From the exponential equation of paralarval growth (Table 1: Eq. 1), a transition at $41.5 \mathrm{~d}$ would correspond to $10.9 \mathrm{~mm}$ ML (Fig. 7). While increment width decreases on the dorsal dome of individuals $>10 \mathrm{~mm} \mathrm{ML}$, increment widths on the rostral zone appear to increase slightly (Fig. 3B), indicating that a transition in growth axis of the statolith occurs at this point.

\section{Mortality estimate}

Natural mortality expressed in terms of age averaged $7.0 \% \mathrm{~d}^{-1}(95 \%$ confidence limits $=4.7$ and $9.3 \%$ $\mathrm{d}^{-1}$ ) for Abralia trigonura paralarvae over the sampling period March 22 to 31, 1986 (Fig. 9).

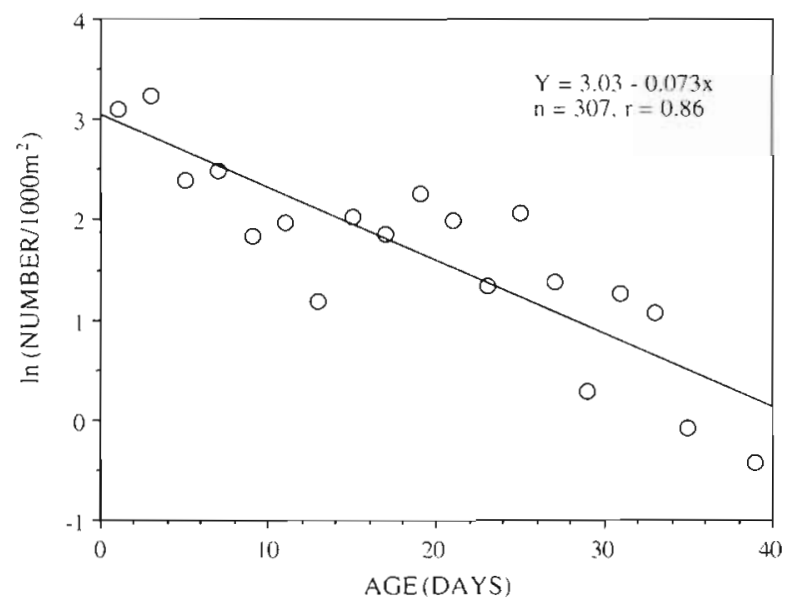

Fig. 9. Abralia trigonura. Mortality rate in terms of age for paralarvae sampled from March 22 to 31,1986 


\section{DISCUSSION}

The validation of ageing techniques is a necessary prerequisite for age and growth estimations from statoliths. In this study, paralarvae reared from the egg for $8 \mathrm{~d}$ have been used to validate daily growth increments for the early stage of Abralia trigonura. The laboratory-reared paralarvae also enabled the determination of statolith size at hatching. Knowing the statolith size at hatching is necessary because some species with relatively large eggs and long incubation periods have increments formed prior to hatching (e.g. Alloteuthis subulata; Morris 1988) which could bias age estimates if improperly interpreted. In Abralia trigonura, increments usually begin to appear after hatching, although 1 increment can be deposited prior to hatching For roughly half the rearing experiment ( 0 to $4 \mathrm{~d}$ ) the squid were nourished by internal yolk. In the latter half of the experiment ( 5 to $8 \mathrm{~d}$ ) the rate of statolith growth declined because paralarvae had depleted yolk reserves and were not receiving any exogenous food. The validation data presented show that increments were formed on a daily basis even though the $12 \mathrm{~h}$ light $12 \mathrm{~h}$ dark photoperiod was the only environmental cue. Increment deposition appears to be unaffected by starvation. Similar results have been found for fishes (Campana \& Neilson 1985), although increment deposition in the otoliths of starved fish may cease if body energy reserves are not sufficient (Jones \& Brothers 1987).

Precise and reproducible age estimates of fieldcaught Abralia trigonura individuals were obtained. Good agreement was demonstrated between replicate counts under light microscopy and SEM. The results from light microscopy were adequate for age estimates of paralarval A. trigonura. The SEM abservations are helpful in resolving increments around the natal region and near the edge of the statolith where interpretation is often difficult with light microscopy. The SEM observations were also required for laboratoryreared $A$. trigonura paralarvae because increments were poorly resolved using light microscopy.

Abralia trigonura is characterized by exponential growth in the paralarval stage, followed by a slower growth stage which is evident by a length of $16 \mathrm{~mm}$ ML. This 2-phase growth relationship is consistent with laboratory studies of benthic octopods (Van Heukelem 1976, Forsythe \& Van Heukelem 1987) and loliginid squids (Yang et al. 1986, Forsythe \& Hanlon 1989). The slower growth phase of post-paralarval A. trigonura apparently begins when they shift to a mesopelagic habitat and begin diel vertical migration. From historical distributional data, post-paralarval A. trigonura occupy a depth range of 390 to $650 \mathrm{~m}$ during the day and 30 to $200 \mathrm{~m}$ at night (Young 1978).
Abralia trigonura as small as $17.0 \mathrm{~mm}$ ML are present in the mesopelagic zone in the day (Young 1978). Presumably, the reduced growth rate in the cold (ca $5{ }^{\circ} \mathrm{C}$ ) mesopelagic habitat, coupled with the energetic requirements of vertical migration, contributes to the slower post-paralarval growth phase.

Transitions in statolith form and microstructural increments of Abralia trigonura were correlated with at least one life-history transition from the paralarval to post-paralarval stages. The end of the average paralarval period is hypothesized to occur at $41.5 \mathrm{~d}$ when increments have diminished in width on the dorsal region of the lateral dome. At this age, a corresponding length of $10.9 \mathrm{~mm}$ ML would result from the paralarval growth curve, similar to the estimate of $11.2 \mathrm{~mm} \mathrm{ML}$ from the intersection of paralarval and post-paralarval growth curves. Apparently, a transition in statolith growth axes coincides with the estimated end of the paralarval period. The developmental shift in statolith form could be associated with a change in behavior, such as a transition to a more active form of swimming External morphological changes, such as the increase in chromatophore number and the appearance of hooks, corroborate the size at the end of the paralarval period (author's pers. obs.). Changes in the width of daily increments mark transitions in the life-history of fish (e.g. Brothers \& McFarland 1981), and the present study is the first to find a correlation between increment width and life-history transitions in squid.

The only other data on the rate of growth from fieldcaught paralarvae are from Illex sp. captured from the Gulf Stream off the Florida coast (Balch et al. 1988). In that study, paralarvae from hatching $(1.0 \mathrm{~mm} \mathrm{ML})$ to $2.9 \mathrm{~mm} \mathrm{ML}$ were estimated to grow exponentially at a rate of $4.3 \% \mathrm{ML} \mathrm{d}^{-1}$ for a period of at least $25 \mathrm{~d}$ based on the assumption that increments are deposited daily. Although temperature data were not presented, IIlex sp. paralarvae grew at significantly slower rates than the comparable-sized Abralia trigonura.

The planktonic duration estimates for an oceanic squid of the present study (i.e. about 40 d) are similar to estimates from laboratory investigations of loliginid (neritic) squids. Hanlon et al. (1987) hypothesized that the appearance of schooling behavior in loliginid squids may be related to the transition from the paralarval to the juvenile or subadult phase. Schooling behavior typically depends on squid size and swimming ability. A transition in life-history stages based on this behavioral change has been estimated to be at 50 to $60 \mathrm{~d}$ for cultured Loligo pealei (4 to $6 \mathrm{~mm} \mathrm{ML;}$ Hanlon et al. 1987), 20 to $40 \mathrm{~d}$ for cultured L. vulgaris (5 to $10 \mathrm{~mm}$ ML; Turk et al. 1986), 40 to $50 \mathrm{~d}$ for cultured $L$. opalescens 8 to $11 \mathrm{~mm} \mathrm{ML;} \mathrm{Yang} \mathrm{et} \mathrm{al.}$ 1986 ) and $40 \mathrm{~d}$ for cultured $L$. forbesi ( 5 to $8 \mathrm{~mm} \mathrm{ML}$ Hanlon et al. 1989). 
The estimate of natural mortality averaged $7.0 \%$ $\mathrm{d}^{-1}$ for Abralia trigonura paralarvae. This average is lower than most estimates for fish species, e.g. feeding-stage mortality of 22 species of marine fishes ranged from 1 to $50 \% \mathrm{~d}^{-1}$ (Houde 1989). Survival in the laboratory has been reported for several species of cultured loliginid squids (e.g. Yang et al. 1986, Hanlon et al. 1989), but apparently no field estimates of mortality exist for comparison. Assumptions for the mortality rate estimate based on the converted length-frequency method are that (1) all age groups analyzed are equally vulnerable to the sampling gear, (2) a continuous and constant level of spawning intensity occurred during the sampling period, (3) no emigration or immigration of paralarvae from the sampling area occurred, (4) the sample for size frequency was random from the population, (5) paralarvae had a constant mortality rate with age and (6) the November 1988 growth rates were equal to the March 1986 growth rates.

Analysis of statolith microstructures is the most effective method for estimating age and studying growth in many natural squid populations. The data presented indicate that statolith increments were deposited daily for Abralia trigonura hatchlings. When extrapolated to all paralarvae, age estimates can be resolved on a daily level, an invaluable analysis for animals which usually do not live longer than 1 yг The ability to sample and age paralarvae means that mortality can be estimated and that problems of survival in the planktonic habitat can be examined. Analysis of spatial and temporal effects on rates of paralarval growth and hatching size may indicate environmental conditions which are favorable for growth and survival. If survival of paralarvae of a given species varies with growth rate, as seems likely, then rates of paralarval growth and survival can be compared to recruitment estimates to indicate whether fluctuations in recruitment are controlled during early life history. In addition, evidence presented in this study suggests that statolith microstructures record the chronology of some life history changes.

Acknowledgements. I am particularly grateful to R. E. Young, J. Hirota and R. L. Radtke who provided laboratory space and invaluable discussions throughout the study. I thank $\mathrm{H}$. Maybaum and D. Rose for help in plankton sorting and rearing experiments, J. Cowen and $\mathrm{T}$ Caravallo for advice and assistance with SEM analysis and the excellent captain and crew of the RV 'Moana Wave' for making field sampling possible. I thank G. W. Boehlert, M. R. Lipinski, D. A. Somerton, R. E. Young, and anonymous reviewers for comments which improved the manuscript

\section{LITERATURE CITED}

Balch, N., Sirois, A., Hurley, G. V. (1988). Growth increments in statoliths from paralarvae of the ommastrephid squid Illex (Cephalopoda: Teuthoidea). Malacologia 29(1). $103-112$

Brothers, E. B., McFarland, W. N. (1981). Correlations between otolith microstructure, growth, and life history transitions in newly recruited french grunts [Haemulon flavolineatum (Desmarest), Haemulidae]. Rapp. P.-v. Réun. Cons. int. Explor. Mer 178: 369-374

Campana, S. E. (1987). Image analysis for microscope-based observations: an inexpensive configuration. Can. Tech. Rep. Fish. Aquat. Sci. No. 1569

Campana, S. E., Neilson, J. D. (1985). Microstructure of fish otoliths. Can. J. Fish. Aquat. Sci. 42: 1014-1032

Clarke, M. R. (1978). The cephalopod statolith - an introduction to its form. J. mar. biol. Ass. U.K. 58: 701-712

Dawe, E. G., O'Dor, R. K., Odense, P. H., Hurley, G. V. (1985). Validation and application of an ageing technique for short-finned squid (Illex illecebrosus). J. Northw. Atl. Fish. Sci. 6: 107-116

Forsythe, J. W., Hanlon, R. T (1989). Growth of the eastern Atlantic squid, Loligo forbesi Steenstrup (Mollusca: Cephalopoda). Aquacult. Fish. Mgmt 20: 1-14

Forsythe, J. W., Van Heukelem, W. F. (1987). Growth. In: Boyle, P. R. (ed.) Cephalopod life cycles, Vol. II: Comparative reviews. Academic Press, London, p. 135-156

Hanlon, R. T., Turk, P. E., Lee, P. G., Yang, W. T (1987). Laboratory rearing of the squid Loligo pealei to the juvenile stage: growth comparisons with fishery data. Fish. Bull. U.S. $85: 163-167$

Hanlon, R. T., Yang, W. T., Turk, P. E., Lee, P. G., Hixon, R. F. (1989). Laboratory culture and estimated life span of the eastern Atlantic squid, Loligo forbesi Steenstrup, 1856 (Mollusca: Cephalopoda). Aquacult. Fish. Mgmt 20: 15-34

Houde, E. D. (1987). Fish early life dynamics and recruitment variability. Am. Fish. Soc. Symp. 2: 17-29

Houde, E. D. (1989). Comparative growth, mortality, and energetics of marine fish larvae: temperature and implied latitudinal effects. Fish. Bull. U.S. 87: 471-495

Jackson, G. D. (1989). The use of statolith microstructures to analyze life-history events in the small tropical cephalopod Idiosepius pygmaeus. Fish. Bull. U.S. 87: 265-272

Jackson, G. D. (1990). Age and growth of the tropical nearshore loliginid squid Sepioteuthis lessoniana determined from statolith growth-ring analysis. Fish. Bull. U.S. 88: $113-118$

Jones, C., Brothers, E. B. (1987). Validation of the otolith increment aging technique for striped bass, Morone saxatilis, larvae reared under suboptimal feeding conditions. Fish. Bull. U.S. 85: 171-178

Kimura, D. K., Chikuni, S. (1987). Mixtures of empirical distributions: an iterative application of the age-length key. Biometrics 43: 23-35

Kristensen, T K. (1980). Periodical growth rings in cephalopod statoliths. Dana 1: 39-51

Lipinski, M., Dawe, E., Natsukari, Y. (1991). Introduction. Practical procedures of squid ageing using statoliths. A laboratory manual. Section 2. In: Jereb, P., Ragonese, S., von Boletzky, S. (eds.) Squid age determination using statoliths. Proc. Internat. Workshop, Instituto di Tecnologia della Pesca e del Pescato (ITPP-CNR), Mazara del Vallo, Italy, 9-14 Oct. 1989. N.T.R.-I.T.P.P. Spec. Publ. 1

Lipinski, M. R. (1978). The age of squids, Illex illecebrosus (Lesueur, 1821) from their statoliths. ICNAF Res. Doc. 78/II/15 Ser. No. 5167: $4 \mathrm{p}$. 
Lipinski, M. R. (1980). Statoliths as a possible tool for squid age determination. NAFO SCR DOC. 80/II/22, 12 p.

Lipinski, M.R. (1986). Methods for the validation of squid age from statoliths. J. mar. biol. Ass. U.K. 66: 505-526

Morris, C. C. (1988). Statolith growth lines and statocyst function in the cephalopoda. Ph.D. thesis, Univ. of Cambridge

Morris, C. C., Aldrich, F. A. (1985). Statolith length and increment number for age determination of Illex illecebrosus (LeSueur, 1821) (Cephalopoda, Ommastrephidae). NAFO Sci. Coun. Studies 9: 101-106

Nakamura, Y., Sakurai, Y (1990). On the daily formation of growth increments in the statolith of Japanese common squid, Todarodes pacificus (Preliminary study). Bull Hokkaido natn. Fish. Res. Inst. No. 54

Natsukari, Y., Nakanose, T., Oda, K. (1988). Age and growth of loliginid squid Photololigo edulis (Hoyle, 1885). J. exp. mar. Biol. Ecol. 116: 177-190

Radtke, R. L. (1983). Chemical and structural characteristics of statoliths from the short-finned squid Illex illecebrosus. Mar. Biol. 76: 47-54

Rodhouse, P. G., Hatfield, E. M. C. (1990). Age determination in squid using statolith growth increments. Fish. Res. (Amst.) 8: 323-334

Roper, C. F. E., Young, R. E. (1975). Vertical distribution of pelagic cephalopods. Smithson. Contr. Zool. 209, 51 p.

Rosenberg, A. A., Wiborg, K. F., Bech I. M. (1981). Growth of Todarodes sagittatus (Lamarck) (Cephalopoda, Ommastrephidae) from the northeast Atlantic, based on counts of statolith growth rings. Sarsia 66: 53-57

Sette, O. E. (1943). Biology of the Atlantic mackeral (Scomber scombrus) of North America. Part I. Early life history in-

This article was submitted to the editor cluding growth, drift, and mortality of the eggs and larval populations. U.S. Fish Wildl. Serv. Fish. Bull. 50(38): 149--237

Sokal, R. R., Rohlf, F. J. (1981). Biometry. W. H. Freeman, San Francisco

Spratt, J. D. (1978). Age and growth of the market squid, Loligo opalescens Berry, in Monterey Bay. Calif. Dept Fish Game Fish Bull. 169: 35-44

Squires, H. J. (1967). Growth and hypothetical age of the Newfoundland bait squid Illex illecebrosus. J. Fish. Res. Bd Can. 24: 1209-1217

Summers, W. C. (1971). Age and growth of Loligo pealei, a population study of the common Atlantic coast squid. Biol. Bull. mar biol. Lab., Woods Hole 141: 189-201

Turk, P. E., Hanlon, R. T., Bradford, L. A., Yang, W. T. (1986). Aspects of feeding, growth and survival of the European squid Loligo vulgaris Lamarck, 1799, reared through the early growth stages. Vie Milieu 36 (1): 9-13

Van Heukelem, W. F. (1976). Growth, bioenergetics and lifespan of Octopus cyanea and Octopus maya. Ph.D. thesis, University of Hawaii, Honolulu

Yang, W. T., Hixon, R. F., Turk, P. E., Krejci, M. E., Hulet, W. H., Hanlon, R. T (1986). Growth, behavior and sexual maturation of the market squid Loligo opalescens, cultured through the life cycle. Fish. Bull. U.S. 84: $771-798$

Young, R. E. (1978). Vertical distribution and photosensitive vesicles of pelagic cephalopods from Hawaiian waters. Fish. Bull. U.S. 76: 583-615

Young, R. E., Harman, R. F. (1988). 'Larva', 'paralarva', and 'subadult' in cephalopod terminology. Malacologia 29(1): $201-207$

Manuscript furst received: December 5, 1991

Revised version accepted: February 27, 1992 